\section{Observatório de políticas públicas sobre regulação internacional de fatores de risco associados a DCNT}

Santana, José Paranaguá de

Núcleo de Estudos sobre Bioética e Diplomacia em Saúde, Fundação Oswaldo Cruz, Brasília/DF

Campos, Roberta de Freitas

Núcleo de Estudos sobre Bioética e Diplomacia em Saúde, Fundação Oswaldo Cruz, Brasília/DF - Brasil. e-mail: roberta.freitas@fiocruz.br

Lopes, Cecília

Núcleo de Estudos sobre Bioética e Diplomacia em Saúde, Fundação Oswaldo Cruz, Brasília/DF

Tasca, Tiago

Núcleo de Estudos sobre Bioética e Diplomacia em Saúde, Fundação Oswaldo Cruz, Brasília/DF

PALAVRAS-CHAVE: Fatores de Risco, Políticas Públicas, Diplomacia em Saúde, Regulação e Fiscalização.

O trabalho apresenta os resultados preliminares do projeto "Observatório de Políticas Públicas sobre Regulação Internacional de Fatores de Risco Associados a DCNT". As novas políticas globais de saúde desenhadas para o cenário pós- 2015 apontam que: para conter a epidemia de doenças crônicas não bastam a atuação dos serviços de saúde e a promoção de hábitos saudáveis, é necessário a regulação estatal de produtos de uso humano que se relacionam com fatores de risco à saúde. $\mathrm{O}$ aperfeiçoamento das políticas regulatórias requer uma análise comparativa de experiências internacionais com enfoque bioético, pois esses produtos, que em muitos casos desconsideram a saúde humana, integram cadeias produtivas transnacionais cuja regulação extrapola as fronteiras dos países. Metodologia: A metodologia para identificação de normas internacionais relacionadas a proteção contra fatores de risco à saúde, incluindo Tabaco, Álcool, Agrotóxico e Alimentos Ultraprocessados, foi definida pela busca de Resoluções emitidas pelos mais altos órgãos decisórios de Organismos Intergovernamentais, isto é da Assembleia Geral das Nações Unidas (ONU), das Assembleias Mundiais da Saúde (OMS) e do Conselho Econômicos Social e Cultural das Nações Unidas (ECOSOC), em suas respectivas base de dados oficiais. O recorte temporal escolhido foi referente aos últimos doze anos (entre 2005 e 2016), período de avanços na regulação estatal em saúde e vigência de resoluções da OMS sobre Doenças Crônicas Não Transmissíveis (DCNT). Foi realizada uma busca entre 2005 e 2016 por Resoluções das Assembleias Gerais da ONU, ECOSOC e OMS em suas respectivas bases de dados, através das palavras-chave: tabaco, alimentos ultraprocessados (sal, açúcar), álcool e agrotóxicos nos idiomas inglês e espanhol. Resultados: Os dados coletados contabilizaram 31 documentos. Referente ao tabaco, dez Resoluções foram identificadas; quatro sobre álcool; sete sobre agrotóxicos e dez sobre alimentos ultraprocessados. Após a consolidação dos documentos, foram realizadas as traduções para o português, elaborados fichamentos, e posteriormente, os fichamentos foram analisados. Para melhor visualização das Resoluções, para cada tema (tabaco, alimentos ultraprocessados, álcool e agrotóxicos) foi desenvolvida uma linha do tempo que apresenta de forma resumida o objetivo central de cada Resolução, a fonte, o número da Resolução e a data de sua aprovação no âmbito do respectivo Organismo Intergovernamental. Por fim, após a análise, baseada em dimensões políticas e técnicas, dispostas nas Resoluções dos Organismos Intergovernamentais ONU, ECOSOC e OMS, foi traçado como resultado preliminar o panorama regulatório internacional de proteção frente aos fatores de risco à saúde relacionados a cada um dos temas: tabaco, álcool, agrotóxicos e alimentos ultraprocessados. Conclusão: Os resultados preliminares comtemplam algumas das atividades desenvolvidas do Observatório de Políticas Públicas sobre Regulação Internacional de Fatores de Risco Associados às Doenças Crônicas Não-Transmissíveis, que incluem, ainda, reuniões e oficinas de trabalho com pesquisadores e colaboradores nacionais e internacionais para intercâmbio, discussão sobre estratégias e caminhos adotados subsequentemente; levantamento de normativas internacionais sobre Regulação de Fatores de Risco à Saúde e criação de uma plataforma web do Observatório inserida no sitio web do Núcleo de Estudos Sobre Bioética e Diplomacia em Saúde (Nethis/Fiocruz/Brasília). A consolidação desse Observatório possibilitará a identificação e sistematização de experiências inovadoras sobre Regulação de Fatores de Risco à Saúde para compartilhamento com instituições técnicocientificas, governamentais e sociedade civil.

AGRADECIMENTOS: Organização Pan-Americana da Saúde (Representação no Brasil)

\section{REFERÊNCIAS}

[1] World Health Organization. Health in the Post-2015 Development Agenda: an analysis of the UN-led thematic consultations, High-level Panel report and sustainable development debate in the context of health [Internet]. Geneva: World Health Organization; 2013 [citado em 2017 Jan 12]. Disponível em: http://apps.who.int/iris/bitstream/10665/85535/1/9789241505963 e ng.pdf.

[2] United Nations. Asamblea General. Political declaration of the High-level Meeting of the General Assembly on the Prevention and Control of Non-communicable Diseases [Internet]. New York: 
United Nations; 2011 set 16 [citado em 2017 Jan 12]. Disponível em: http://www.un.org/ga/search/view_doc.asp?symbol=A/66/L.11. 